\title{
KLASIFIKASI CITRA BATIK INDONESIA DAN MALAYSIA DENGAN METODE MODIFIED DISCRIMINANT ANALYSIS
}

\author{
Cynthia ${ }^{1}$, Janson Hendryli ${ }^{2}$, Dyah Erny Herwindiati ${ }^{3}$ \\ ${ }^{1,2,3}$ Program Studi Teknik Informatika, Fakultas Teknik Informasi Universitas Tarumanagara \\ Jl. Let. Jend. S. Parman No. 1, Jakarta 11440 Indonesia \\ E-mail:'rahardjo.cynthia@hotmail.com, ${ }^{2}$ jansonh@fti.untar.ac.id, ${ }^{3}$ dyahh@fti.untar.ac.id
}

\begin{abstract}
Abstrak
Aplikasi klasifikasi citra batik Indonesia dan Malaysia dengan metode Linear Discriminant Analysis (LDA) dan Modified Discriminant Analysis (MDA) merupakan aplikasi pengenalan yang digunakan untuk mengklasifikasi citra berupa batik. Pembuatan aplikasi ini menggunakan bahasa pemrograman Java untuk menjalankan metode pengambilan fitur yaitu Color Histogram dan Daubechies Wavelet dan metode pengklasifikasian yaitu LDA dan MDA. Pengujian dilakukan dengan metode blackbox testing dan matriks konfusi. Pengujian dilakukan dengan menggunakan fitur ciri warna, ciri tekstur, dan gabungan dari citra latih dan citra uji baru. Hasil persentase pengujian terbaik adalah pengujian dengan menggunakan ciri warna, sedangkan dengan ciri tekstur dan gabungan mendapatkan hasil persentase pengujian sedikit rendah.
\end{abstract}

Kata Kunci - Color Histogram, Daubechies Wavelet, Java, Linear Discriminant Analysis, Modified Discriminant Analysis

\begin{abstract}
The application of Indonesian and Malaysian batik image classification using the Linear Discriminant Analysis (LDA) and Modified Discriminant Analysis (MDA) method is an introduction application that is used to classify images in the form of batik. Making this application uses the Java programming language to run feature retrieval methods, namely Color Histogram and Daubechies Wavelet and classification methods, namely LDA and MDA. Testing is done by blackbox testing method and confusion matrix. Tests are performed using color features, texture features, and a combination of training images and new test images. The best percentage test results are testing using color features, whereas with texture and the combination of bothfeatures get a slightly lower test percentage result.
\end{abstract}

Keywords - Color Histogram, Daubechies Wavelet, Java, Linear Discriminant Analysis, Modified Discriminant Analysis

\section{PENDAHULUAN}

Batik merupakan salah satu seni tradisional Indonesia dalam menghias kain dengan cara menggambar atau mencetak pola-pola dan motif tertentu pada kain. Batik adalah kerajinan yang memiliki nilai tinggi dan telah menjadi bagian budaya Indonesia (khususnya Jawa) sejak lama. Setiap daerah di Indonesia memiliki motif batik yang berbeda-beda, dan keunikan tersebut dikarenakan pengaruh budaya masyarakat setempat serta kepercayaan akan motif yang memiliki makna tersendiri. Beberapa peninggalan sejarah Indonesia diketahui merupakan relasi pertukaran antara Kerajaan Melayu di Jambi dan kota-kota pesisir Jawa. Daerah penghasil batik 
di pesisir utara Jawa telah mempengaruhi batik Jambi, yang kemudian mempengaruhi kerajinan batik di Semenanjung Malaya. Meskipun batik Indonesia dan batik Malaysia cukup berbeda, namun tidak dapat dipungkiri bahwa sebagian besar masyarakat Indonesia tidak dapat mengenali motif batik khas dari Indonesia. Untuk itu, dibutuhkan suatu aplikasi yang dapat memudahkan masyarakat untuk dapat mengenali motif batik Indonesia dan batik dari negara lain yang disini merupakan batik Malaysia. Dengan adanya sebuah aplikasi yang dapat membedakan motif batik Indonesia dan Malaysia, diharapkan dapat menarik minat masyarakat dalam mempelajari motif batik Indonesia dan tidak salah mengenalinya dengan batik milik Malaysia, begitu pula sebaliknya, dan juga diharapkan tidak dapat terjadi lagi pengambilalihan seni tradisional Indonesia oleh Malaysia.

\section{METODE PENELITIAN}

Dalam pembuatan aplikasi klasifikasi citra batik Indonesia dan Malaysia dilakukan berdasarkan metode yang ada seperti yang dijelaskan di bawah ini.

\subsection{Color Histogram}

Metode Color Histogram berkaitan erat dengan proses pengolahan citra digital. Color Histogram adalah representasi dari distribusi nilai-nilai warna dalam citra digital. Dalam citra digital, Color Histogram mewakili jumlah piksel warna pada rentang nilai tertentu yang mencakup ruang warna citra digital tersebut.

Langkah-langkah metode Color Histogram akan dijelaskan sebagai berikut:

1. Membagi citra berdasarkan jenis ruang warna RGB.

2. Menentukan jumlah bin yang diinginkan dengan rumus:

Keterangan:

$$
\mathbf{X}_{\mathbf{i} * \text { range }} \ldots \mathbf{X}_{\mathbf{i} * \text { range }+ \text { index }}
$$

$\mathrm{i}=$ bin ke- $j$

range $=\frac{256}{\text { bin }}$

index $=0 \mathrm{~s} / \mathrm{d}\left(\frac{256}{\mathrm{bin}}-1\right)$

3. Menghitung frekuensi banyak piksel menurut bin yang telah ditentukan dan membuat histogram untuk setiap kelompok frekuensi yang dihasilkan.

4. Nilai pada histogram di bentuk menjadi sebuah vektor $1 \times$ (j.bin) untuk masing-masing warna kemudian ketiga vektor di gabungkan menjadi $1 \mathrm{x}(3 \mathrm{xj}$. bin) yang merupakan hasil dari fitur Color Histogram.

\subsection{Daubechies Wavelet}

Wavelet merupakan suatu metode yang dapat digunakan untuk menganalisis sinyal-sinyal non-stasioner, selain itu digunakan juga untuk menapis data, menghilangkan sinyal-sinyal (data) yang tidak diinginkan atau meningkatkan mutu kualitas data. Transformasi wavelet menggunakan dua komponen penting dalam melakukan transformasi yakni fungsi skala (scalling function) dan fungsi wavelet (wavelet function). Fungsi skala disebut juga sebagai lowpass filter berguna untuk mengambil citra dengan gradasi intensitas yang halus dan perbedaan intensitas yang tinggi akan dikurangi atau dibuang, sedangkan fungsi wavelet disebut juga sebagai highpass filter berguna untuk mengambil citra dengan gradasi intensitas yang rendah akan dikurangi atau dibuang.

Daubechies wavelet yang umum digunakan adalah D2 sampai dengan D20. Dalam kasus ini digunakan Daubechies D4 wavelet, dengan nilai 4 yang menyatakan nomor indeks wavelet. Nomor indeks ini mengacu pada banyaknya masing-masing koefisien lowpass filter $\mathrm{h}[\mathrm{n}]$ dan 
highpass filter $\mathrm{g}[\mathrm{n}]$ yang dimiliki wavelet. Sehingga dapat diartikan bahwa Daubechies D4 wavelet memiliki masing-masing 4 koefisien $\mathrm{h}[\mathrm{n}]$ dan $\mathrm{g}[\mathrm{n}]$. Koefisien scalling function pada Daubechies D4 wavelet adalah:

$h_{0}=\frac{1+\sqrt{3}}{4 \sqrt{2}}, h_{1}=\frac{3+\sqrt{3}}{4 \sqrt{2}}, h_{2}=\frac{3-\sqrt{3}}{4 \sqrt{2}}, h_{3}=\frac{1-\sqrt{3}}{4 \sqrt{2}}$

$h_{0}=0.4829629131, h_{1}=0.8365163037$,

$h_{2}=0.2241438680, h_{3}=-0.1294095226$

Koefisien wavelet function adalah:

$g_{0}=h_{31}, g_{1}=-h_{2}, g_{2}=h_{1}, g_{3}=-h_{0}$

Sehingga nilai koefisiennya sebagai berikut:

$g_{0}=0.1294095226, g_{1}=-0.2241438680$,

$g_{2}=0.8365163037, g_{3}=-0.4829629131$

Scalling function dan wavelet function dihitung dengan mengambil hasil perkalian koefisien $\mathrm{h}[\mathrm{n}]$ dan $\mathrm{g}[\mathrm{n}]$ dengan sinyal yang akan dianalisis. Persamaannya ditunjukkan sebagai berikut:

$\mathrm{a}_{\mathrm{i}}=\mathrm{h}_{0} \mathrm{~s}_{2 \mathrm{i}}+\mathrm{h}_{1} \mathrm{~s}_{2 \mathrm{i}+1}+\mathrm{h}_{2} \mathrm{~s}_{2 \mathrm{i}+2}+\mathrm{h}_{3} \mathrm{~s}_{2 \mathrm{i}+3}$,

$c_{i}=g_{0} s_{2 i}+g_{1} s_{2 i+1}+g_{2} s_{2 i+2}+g_{3} s_{2 i+3}$

keterangan:

$\mathrm{a}_{\mathrm{i}}=$ scalling function

$\mathrm{c}_{\mathrm{i}}=$ wavelet function

$\mathrm{s}=$ sinyal yang akan dianalisis

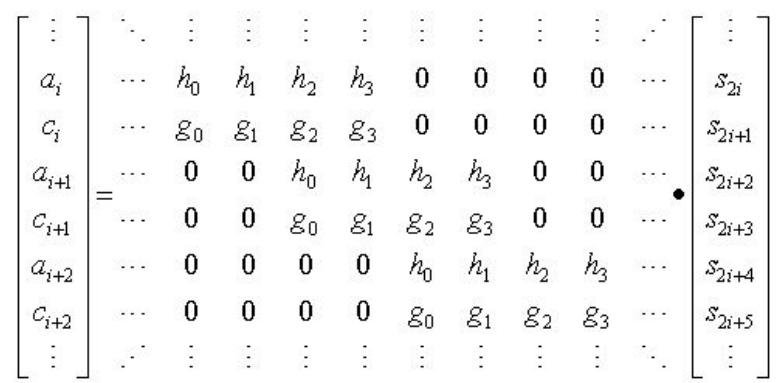

Gambar 1 Daubechies Wavelet Transform Matrix

Sumber: Ian Kaplan, Transform Matrix, http://bearcave.com/misl/misl_tech/wavelets/matrix/index.html, 30 September 2011.

Hasil dari penggunaan transformasi Daubechies wavelet berupa informasi citra yang terbagi menjadi aproksimasi dan detail sub signal. Terdapat 3 detail subsignal yaitu detail horizontal, vertikal, dan diagonal. Pada Gambar 2 dapat dilihat LL merupakan bagian aproksimasi, HL merupakan bagian detail horizontal, LH merupakan bagian detail vertikal, HH merupakan bagian detail diagonal.

\begin{tabular}{|c|c|c|c|c|}
\hline \multirow{2}{*}{ LL } & \multirow{2}{*}{ HL } & LL & HL & \multirow{2}{*}{ HL } \\
\hline & & LH & Hн & \\
\hline LH & HH & & & $\mathbf{H H}$ \\
\hline
\end{tabular}

Gambar 2 Tampilan Hasil Transformasi Daubechies Wavelet

Sumber: Satish Sampath, Classifying image data, http://www.debugmode.com/imagecmp/classify.htm, 22 Oktober 2001. 


\subsection{Linear Discriminant Analysis dan Modified Discriminant Analysis}

Linear Discriminant Analysis adalah yang paling umum digunakan sebagai teknik reduksi dimensional dalam tahap pre-processing untuk pengklasifikasian pola dan aplikasi machine learning. Tujuannya adalah untuk memproyeksikan dataset ke ruang dimensi yang lebih rendah dengan keterpisahan kelas yang baik untuk menghindari overfitting dan juga mengurangi biaya komputasi. Seringkali tujuan dari LDA adalah memproyeksikan ruang fitur (sample dataset $n$ dimensi) ke subruang $\mathrm{k}$ yang lebih kecil (dimana $\mathrm{k} \leq \mathrm{n}-1$ ) sambil mempertahankan informasi kelas diskriminatif. Secara umum, pengurangan dimensi tidak hanya membantu mengurangi biaya komputasi untuk tugas klasifikasi yang diberikan, tetapi juga dapat membantu untuk menghindari overfitting dengan meminimalkan kesalahan dalam estimasi parameter. LDA dapat dideskripsikan sebagai algoritma "supervised" dan menghitung arah (diskriminan linear) yang akan mewakili sumbu yang memaksimalkan pemisah antara beberapa kelas.

Pada LDA diasumsikan data terdistribusi normal, feature secara statistik independen, dan matriks kovarian identik untuk seluruh kelas. Maka setelah dataset telah dipersiapkan dan feature dari Color Histogram dan Transformasi Daubechies Wavelet sudah didapatkan, kemudian masuk ke tahap pengerjaan LDA yang terdiri atas:

1. Pada tahap awal ini, dimulai dengan perhitungan simpel dari rata-rata vektor $\mathrm{m}_{\mathrm{i}}$, namun pada perhitungan LDA disini akan dilakukan perubahan dengan mengganti perhitungan rata-rata menjadi perhitungan dengan quartil 1 pada 2 kelas yang berbeda. Maka estimator quartil 1 dari metode dirumuskan sebagai:

$$
\mathbf{m}_{\mathbf{i}}=\frac{1}{2 * n} \sum_{i=1}^{n} x_{i}
$$

Keterangan:

$\mathrm{m}_{\mathrm{i}} \quad$ : Q1 vektor sample

$\mathrm{n}$ : banyak data

$\mathrm{x}_{\mathrm{i}} \quad$ : nilai data ke-i

2. Pembentukan fungsi diskriminan diawali dengan menentukan matriks within group variancecovariance yang didapatkan dengan membagi setiap nilai pada matriks scatter within group $\left(\mathrm{S}_{\mathrm{W}}\right)$ dengan hasil pengurangan jumlah data dan jumlah kelompok. Matriks $\mathrm{S}_{\mathrm{W}}$ merupakan matriks penyebaran dalam suatu grup. Matriks $S_{W}$ dihitung dengan persamaan:

$$
\begin{gathered}
S_{W}=\sum_{i=1}^{c} S_{i} \\
S_{i}=\sum_{\boldsymbol{x} \in D_{i}}^{n}\left(\boldsymbol{x}-\boldsymbol{m}_{i}\right)\left(\boldsymbol{x}-\boldsymbol{m}_{i}\right)^{T}
\end{gathered}
$$

Keterangan:
$\mathrm{S}_{\mathrm{W}}$ : matriks scatter within group

$\mathrm{X} \quad$ : vektor fitur citra batik

$\mathrm{m}_{\mathrm{i}} \quad$ : Q1 vektor sample

3. Tahap selanjutnya adalah menentukan nilai koefisienfungsi klasifikasi. Koefisien fungsi klasifikasi $\left(\mathrm{C}_{\mathrm{j}}\right)$ diperoleh dengan mengalikan invers matriks $\mathrm{W}$ dan vektor $\mathrm{Q} 1$ seperti persamaan berikut:

Keterangan:

$$
\mathbf{C}_{\mathbf{j}}=\mathbf{W}^{-1} * \mathbf{m}_{\mathbf{i}}
$$

$\mathrm{C}_{\mathrm{j}} \quad$ : koefisien fungsi klasifikasi

$\mathrm{W}^{-1}$ : invers matriks within group variance-covariance 
$\mathrm{m}_{\mathrm{i}} \quad$ : Q1 vektor sample

4. Selanjutnya adalah menghitung nilai konstanta untuk setiap kelompok. Nilai konstanta untuk setiap kelompok $\left(\mathrm{C}_{\mathrm{j}}\right)$ dapat diperoleh dengan menggunakan persamaan berikut:

Keterangan:

$$
\mathbf{C}_{\mathrm{j} 0}=\left(-\frac{1}{2}\right) C_{j}^{T} \mathbf{m}_{\mathrm{i}}
$$

$\mathrm{C}_{\mathrm{j} 0}$ : konstanta

$C_{j}^{T} \quad$ : transpose koefisien fungsi klasifikasi

$\mathrm{m}_{\mathrm{i}} \quad$ : Q1 vektor sampel

5. Fungsi klasifikasi untuk setiap kelompok disusun berdasarkan persamaan berikut:

$$
\mathbf{C}=\mathbf{C}_{0}+\mathbf{C}_{1} \mathbf{X}_{1}+\mathbf{C}_{2} \mathbf{X}_{2}+\ldots+\mathbf{C}_{\mathrm{i}} \mathbf{X}_{\mathbf{i}}
$$

Keterangan:

C : fungsi klasifikasi untuk setiap kelompok

$\mathrm{C}_{0} \quad$ : konstanta

$\mathrm{C}_{\mathrm{i}} \quad$ : koefisien fungsi klasifikasi

$\mathrm{X}$ : nilai prediktor atau variabel tak bebas yang akan diklasifikasi

i : jumlah predictor

Setelah terbentuk fungsi klasifikasi untuk setiap kelompok, maka fungsi tersebut siap digunakan untuk mengklasifikasikan obyek baru ke dalam salah satu kelompok berdasarkan nilai klasifikasi tertinggi.

\section{HASIL DAN PEMBAHASAN}

Pengujian model klasifikasi dilakukan dengan menggunakan matriks konfusi, nilai precision, recall dan F1-score yang memperlihatkan hasil klasifikasi dengan menggunakan seluruh fitur dan fungsi klasifikasi LDA dan MDA.

\subsection{Pengujian Model Klasifikasi}

Pengujian dilakukan untuk mengetahui besar akurasi dari citra uji terhadap citra latih. Hasil yang diharapkan adalah program yang dapat mengenali citra batik yang dimasukkan secara tepat, sehingga hasil pengenalan dapat diketahui citra batik manakah yang dimasukkan. Citra yang akan diuji adalah citra dari dataset pelatihan yang berjumlah 380 citra batik Indonesia dan 364 citra batik Malaysia, serta citra baru untuk pengujian yang berjumlah 176 citra batik Indonesia dan 65 citra batik Malaysia. Sehingga total citra yang akan diujikan adalah sebanyak 985 citra yang terdiri atas 556 citra batik Indonesia dan 429 citra batik Malaysia.

Hasil pengujian dilihat dari nilai yang dihasilkan dari fitur yang dimasukkan ke fungsi klasifikasi, yaitu fitur dari color histogram, Daubechies wavelet dan fitur gabungan yang dimasukkan ke fungsi klasifikasi dari metode LDA dan MDA. Jika nilai lebih besar di penggunaan fungsi Indonesia, maka citra batik dinyatakan sebagai batik Indonesia, dan jika nilai lebih besar di penggunaan fungsi Malaysia, maka citra batik dinyatakan sebagai batik Malaysia.

\subsubsection{Pengujian Citra Uji dengan Fitur Color Histogram}

Pengujian skema pertama dilakukan dengan menggunakan fungsi LDA dan MDA dari fitur Color Histogram yang menggunakan citra latih berjumlah 380 citra batik Indonesia dan 364 citra batik Malaysia. Hasil pelatihan berupa satu vektor panjang berukuran 1x193 yang 
merupakan model atau fungsi diskriminan dari metode Linear Discriminant Analysis dan Modified Discriminant Analysis untuk masing-masing dari citra batik Indonesia dan Malaysia.

Pengujian dilakukan pada dataset 985 citra uji yang terdiri dari 556 citra batik Indonesia dan 429 citra batik Malaysia.Hasil pengujian data latih dapat dilihat pada Tabel 1 dan Tabel 2 dan hasil pengujian data latih dapat dilihat pada Tabel 3 dan Tabel 4.

Tabel 1 Hasil Pengujian Data Latih dengan Fitur Color Histogram dan Fungsi LDA.

\begin{tabular}{|c|c|c|c|}
\hline & Precision & Recall & F1-score \\
\hline Indonesia & 1 & 0.510752688 & 0.67616 \\
\hline Malaysia & 0 & $\mathrm{NaN}$ & $\mathrm{NaN}$ \\
\hline Average / Total & 0.5107527 & $\mathrm{NaN}$ & $\mathrm{NaN}$ \\
\hline
\end{tabular}

Tabel 2 Hasil Pengujian Data Latih dengan Fitur Color Histogram dan Fungsi MDA.

\begin{tabular}{|c|c|c|c|}
\hline & Precision & Recall & F1-score \\
\hline Indonesia & 1 & 0.510752688 & 0.67616 \\
\hline Malaysia & 0 & $\mathrm{NaN}$ & $\mathrm{NaN}$ \\
\hline Average / Total & 0.5107527 & $\mathrm{NaN}$ & $\mathrm{NaN}$ \\
\hline
\end{tabular}

Tabel 3 Hasil Pengujian Data Baru dengan Fitur Color Histogram dan Fungsi LDA.

\begin{tabular}{|c|c|c|c|}
\hline & Precision & Recall & F1-score \\
\hline Indonesia & 1 & 0.728033473 & 0.84262 \\
\hline Malaysia & 0 & $\mathrm{NaN}$ & $\mathrm{NaN}$ \\
\hline Average / Total & 0.7280335 & $\mathrm{NaN}$ & $\mathrm{NaN}$ \\
\hline
\end{tabular}

Tabel 4 Hasil Pengujian Data Baru dengan Fitur Color Histogram dan Fungsi MDA.

\begin{tabular}{|c|c|c|c|}
\hline & Precision & Recall & F1-score \\
\hline Indonesia & 1 & 0.728033473 & 0.84262 \\
\hline Malaysia & 0 & $\mathrm{NaN}$ & $\mathrm{NaN}$ \\
\hline Average / Total & 0.7280335 & $\mathrm{NaN}$ & $\mathrm{NaN}$ \\
\hline
\end{tabular}

\subsubsection{Pengujian Citra Uji dengan Fitur Daubechies Wavelet}

Pengujian skema kedua dilakukan dengan menggunakan fungsi LDA dan MDA dari fitur Daubechies wavelet yang menggunakan citra latih berjumlah 380 citra batik Indonesia dan 364 citra batik Malaysia. Hasil pelatihan berupa satu vektor panjang berukuran 1x1601 yang merupakan model atau fungsi diskriminan dari metode Linear Discriminant Analysis dan Modified Discriminant Analysis untuk masing-masing dari citra batik Indonesia dan Malaysia.

Pengujian dilakukan pada dataset 985 citra uji yang terdiri dari 556 citra batik Indonesia dan 429 citra batik Malaysia. Hasil pengujian data latih dapat dilihat pada Tabel 5 dan Tabel 6 dan hasil pengujian data baru dapat dilihat pada Tabel 7 dan Tabel 8.

Tabel 5 Hasil Pengujian Data Latih dengan Fitur Daubechies Wavelet dan Fungsi LDA.

\begin{tabular}{|c|c|c|c|}
\hline & Precision & Recall & F1-score \\
\hline Indonesia & 0.40789 & 0.5081967 & 0.45255 \\
\hline Malaysia & 0.58791 & 0.4874715 & 0.533 \\
\hline Average / Total & 0.49596 & 0.4980569 & 0.49191 \\
\hline
\end{tabular}


Tabel 6 Hasil Pengujian Data Latih dengan Fitur Daubechies Wavelet dan Fungsi MDA.

\begin{tabular}{|c|c|c|c|}
\hline & Precision & Recall & F1-score \\
\hline Indonesia & 0.5921053 & 0.5125284 & 0.54945 \\
\hline Malaysia & 0.4120879 & 0.4918032 & 0.44843 \\
\hline Average / Total & 0.5040323 & 0.5023887 & 0.50003 \\
\hline
\end{tabular}

Tabel 7 Hasil Pengujian Data Baru dengan Fitur Daubechies Wavelet dan Fungsi LDA.

\begin{tabular}{|c|c|c|c|}
\hline & Precision & Recall & F1-score \\
\hline Indonesia & 0.454023 & 0.79 & 0.57664 \\
\hline Malaysia & 0.6769231 & 0.3165467 & 0.43137 \\
\hline Average / Total & 0.5146444 & 0.6612365 & 0.53713 \\
\hline
\end{tabular}

Tabel 8 Hasil Pengujian Data Baru dengan Fitur Daubechies Wavelet dan Fungsi MDA.

\begin{tabular}{|c|c|c|c|}
\hline & Precision & Recall & F1-score \\
\hline Indonesia & 0.545977 & 0.6834532 & 0.60703 \\
\hline Malaysia & 0.3230769 & 0.21 & 0.25455 \\
\hline Average / Total & 0.4853556 & 0.5546898 & 0.51117 \\
\hline
\end{tabular}

\subsubsection{Pengujian Citra Uji dengan Fitur Gabungan}

Pengujian skema ketiga dilakukan dengan menggunakan fungsi LDA dan MDA dari gabungan fitur Color Histogram dan fitur Daubechies wavelet yang menggunakan citra latih berjumlah 380 citra batik Indonesia dan 364 citra batik Malaysia. Hasil pelatihan berupa satu vektor panjang berukuran 1x1793 yang merupakan model atau fungsi diskriminan dari metode Linear Discriminant Analysis dan Modified Discriminant Analysis untuk masing-masing dari citra batik Indonesia dan Malaysia.

Pengujian dilakukan pada dataset 985 citra uji yang terdiri dari 556 citra batik Indonesia dan 429 citra batik Malaysia. Hasil pengujian data latih dapat dilihat pada Tabel 9 dan Tabel 10 dan hasil pengujian data baru dapat dilihat pada Tabel 11 dan Tabel 12.

Tabel 9 Hasil Pengujian Data Latih dengan Fitur Gabungan dan Fungsi LDA.

\begin{tabular}{|c|c|c|c|}
\hline & Precision & Recall & F1-score \\
\hline Indonesia & 0.5921053 & 0.512528474 & 0.54945 \\
\hline Malaysia & 0.4120879 & 0.491803279 & 0.44843 \\
\hline Average/ Total & 0.5040323 & 0.502388728 & 0.50003 \\
\hline
\end{tabular}

Tabel 10 Hasil Pengujian Data Latih dengan Fitur Gabungan dan Fungsi MDA.

\begin{tabular}{|c|c|c|c|}
\hline & Precision & Recall & F1-score \\
\hline Indonesia & 0.4078947 & 0.508196721 & 0.45255 \\
\hline Malaysia & 0.5879121 & 0.487471526 & 0.533 \\
\hline Average / Total & 0.4959677 & 0.498056975 & 0.49191 \\
\hline
\end{tabular}

Tabel 11 Hasil Pengujian Data Baru dengan Fitur Gabungan dan Fungsi LDA.

\begin{tabular}{|c|c|c|c|}
\hline & Precision & Recall & F1-score \\
\hline Indonesia & 0.545977 & 0.683453237 & 0.60703 \\
\hline Malaysia & 0.3230769 & 0.21 & 0.25455 \\
\hline Average / Total & 0.4853556 & 0.554689805 & 0.51117 \\
\hline
\end{tabular}

Tabel 12 Hasil Pengujian Data Baru dengan Fitur Gabungan dan Fungsi MDA.

\begin{tabular}{|c|c|c|c|}
\hline & Precision & Recall & F1-score \\
\hline Indonesia & 0.454023 & 0.79 & 0.57664 \\
\hline Malaysia & 0.6769231 & 0.316546763 & 0.43137 \\
\hline Average / Total & 0.5146444 & 0.661236567 & 0.53713 \\
\hline
\end{tabular}




\subsection{Pengujian Citra Live}

Pada sistem yang telah dibuat terdapat pengambilan citra yang dilakukan secara langsung atau live menggunakan webcam. Fitur ini bertujuan untuk mempermudah pengguna dalam melakukan proses pengujian citra batik tanpa harus menyimpan citra sebelumnya dan kemudian diunggah pada sistem. Dengan fitur ini, pengguna hanya perlu mengambil citra dengan webcam dan kemudian langsung digunakan pada proses pengujian menggunakan metode yang tersedia.

Hasil pengujian citra live dapat dipengaruhi beberapa hal, diantaranya posisi pengambilan citra dan pencahayaan. Posisi pengambilan citra menyebabkan potongan citra berubah dan berbeda dari satu citra ke citra lainnya sehingga tekstur yang didapatkan jadi berbeda dan menyebabkan hasil pengenalan citra dapat berbeda. Kemudian pencahayaan pada saat pengambilan citra juga mempengaruhi hasil pengenalan, karena pada saat citra diambil dan pencahayaan kurang atau berlebih menyebabkan warna pada citra berubah, seperti saat pencahayaan kurang menyebabkan warna citra menjadi gelap.

\subsection{Pembahasan Hasil Pengujian}

Hasil pengenalan dengan metode Linear Discriminant Analysis dan Modified Discriminant Analysis tidak memiliki perbedaan yang jauh, baik untuk penggunaan fitur ciri warna, ciri tekstur, ataupun fitur gabungan. Seperti pada saat penggunaan fitur gabungan untuk pengujian citra batik menggunakan data latih didapatkan hasil akurasi sebesar $50.40 \%$ untuk fungsi LDA dan $49.59 \%$ untuk fungsi MDA, sedangkan untuk pengujian citra batik menggunakan data baru didapatkan hasil akurasi sebesar $48.53 \%$ untuk fungsi LDA dan $51.46 \%$ untuk fungsi MDA. Kemudian saat penggunaan fitur ciri tekstur untuk pengujian citra batik menggunakan data latih didapatkan hasil akurasi sebesar $49.59 \%$ untuk fungsi LDA dan $50.40 \%$ untuk fungsi MDA, sedangkan untuk pengujian citra batik menggunakan data baru didapatkan hasil akurasi sebesar 51.46\% untuk fungsi LDA dan 48.53\% untuk fungsi MDA. Dari hasil akurasi tersebut dapat dilihat bahwa fungsi LDA dan MDA keduanya memiliki kelebihan dan kekurangannya masing-masing, namun sudah dapat dikatakan bahwa kedua fungsi tersebut cukup baik dalam melakukan klasifikasi citra batik dengan menghasilkan akurasi berkisar 50 persen.

Dari sisi penggunaan fitur, untuk ketiga fitur yang digunakan dapat dikatakan bahwa fitur ciri warna menggunakan metode color histogram merupakan fitur yang terbaik dalam proses klasifikasi yang dilakukan pada sistem dibandingkan dengan penggunaan fitur ciri tekstur dengan metode daubechies wavelet dan fitur gabungan ciri warna dan tekstur. Hal ini dikarenakan hasil persentase yang didapatkan secara keseluruhan yang terbaik adalah yang dimiliki dengan penggunaan fitur ciri warna, yaitu untuk pengujian citra batik menggunakan data latih didapatkan hasil $51.07 \%$ sedangkan untuk pengujian citra batik menggunakan data baru didapatkan hasil $72.80 \%$. Dengan hasil persentase tersebut maka dapat dikatakan bahwa klasifikasi citra batik menggunakan fitur ciri warna dengan metode color histogram dapat melakukan proses klasifikasi citra batik dengan baik.

Kesalahan pengenalan pada citra batik dapat dikarenakan adanya kemiripan yang dimiliki oleh batik Indonesia dan Malaysia. Hal ini bisa dikarenakan masih adanya pengaruh dari batik Indonesia yang dimiliki oleh batik Malaysia, baik secara warna ataupun tekstur. Seperti pada ciri tekstur batik Indonesia yang memiliki ciri khas tektur berupa pola yang teratur atau motif yang geometris, pada beberapa citra batik Malaysia terdapat tekstur yang serupa. Maka dengan hal tersebut citra batik Indonesia yang dapat dikenali adalah citra batik Indonesia yang dengan ciri khas nya yaitu motif yang geometris atau pola yang teratur. Sedangkan untuk citra batik Malaysia dapat dikenali dengan ciri tekstur yang tidak geometris dan pola yang tidak teratur, sedangkan untuk pola yang teratur pada citra batik Malaysia dikenali sebagai citra batik 
Indonesia. Dan pada ciri warna, batik Indonesia memiliki berbagai macam warna, namun pada umumnya batik Indonesia paling banyak berwarna cokelat sedangkan pada batik Malaysia memiliki warna-warna terang yang lebih bervariasi. Maka citra batik Indonesia dapat dikenali dengan warna yang dominan gelap, sedangkan untuk citra batik Malaysia dapat dikenali dengan warna yang dominan terang.

\section{KESIMPULAN}

Kesimpulan yang diperoleh dari pembuatan aplikasi klasifikasi citra batik Indonesia dan Malaysia dari perencanaan, analisis, pembuatan, dan pengujian adalah sebagai berikut:

1. Pengenalan citra batik menggunakan fitur Color Histogram dengan fungsi LDA dan dengan fungsi MDA memberikan hasil pengenalan yang terbaik dibandingkan dengan menggunakan fitur Daubechies wavelet dan fitur gabungan, dengan hasil persentase $51.07 \%$ untuk pengujian data latih dan $72.80 \%$ untuk pengujian data baru.

2. Kedua fungsi diskriminan atau fungsi klasifikasi yang digunakan dari metode Linear Discriminant Analysis dan Modified Discriminant Analysis tidak memiliki hasil persentase pengenalan yang berbanding jauh, sehingga tidak dapat dikatakan penggunaan metode manakah yang lebih baik. Karena masing-masing metode memiliki hasil yang lebih baik pada penggunaan fitur dan data yang berbeda.

3. Data citra yang digunakan untuk proses pelatihan dan pengujian tidak seimbang dan terlalu sedikit sehingga menjadi salah satu faktor yang menyebabkan dihasilkannya tingkat akurasi yang kecil.

4. Kemiripan yang dimiliki oleh citra batik Indonesia dan Malaysia, baik dalam ciri tekstur seperti pola teratur atau geometris yang dimiliki batik Indonesia ataupun ciri warna seperti warna yang bervariasi dimiliki batik Malaysia juga menjadi salah satu faktor yang menyebabkan dihasilkannya tingkat akurasi yang kecil.

5. Pada proses pengujian citra live terdapat faktor-faktor yang mempengaruhi hasil pengenalan citra, diantaranya adalah posisi pengambilan citra dan pencahayaan saat pengambilan citra.

\section{UCAPAN TERIMA KASIH}

Terima kasih saya ucapkan kepada pembimbing penulis dalam pembuatan makalah ini, serta kepada seluruh dosen dan karyawan Fakultas Teknologi Informasi UniversitasTarumanagara yang sudah membantu dalam proses perkuliahan penulis. Terima kasih juga kepada segenap keluarga, teman dan pendahulu saya yang sudah memberikan berbagai bentuk support dalam proses pembuatan makalah ini.

\section{DAFTAR PUSTAKA}

[1] Abasi, Y. W. Kompresi Citra Menggunakan Transformasi Wavelet, https://www.researchgate.net/publication/260555075_kompresi_image_menggunakan_31_ fungsi_wavelet, 28 September 2011. Diakses 3 September 2018.

[2] Bellio, R. An Introduction to Robust Estimation with $R$ Function, https://www. researchgate.net/publication/228906268_An_introduction_to_robust_estimation_with_R_f unctions, Oktober 2005. Diakses 5 September 2018.

[3] Chakravarti, R \& Xiannong, M. A Study Of Color Histogram Based Images Retrieval, Las Vegas: $6^{\text {th }}$ International Conference on Information Technology, 2009.

[4] Christian, S, Pengelompokan Data Menggunakan Jackknife Resampling dengan Ukuran Pusat Mean, Median, dan Kuartil, https://scholar.google.com/scholar?hl=en\&as_sdt=0,5\& cluster $=4149790689581528214,25$ September 2015. Diakses 10 Januari 2019. 
[5] Anonim. Dekomposisi Transformasi Wavelet, https://www.researchgate.net/publication/ 318292664, 24 Agustus 2011. Diakses 3 September 2018.

[6] Fadli, M. Motif Batik Geometris, http://motif-batik.tl.web.id/id1/2432-1812/MotifBatik_127990_motif-batik-tl.html\#Motif-motif_Batik, 5 Mei 2014. Diakses 30 Agustus 2018.

[7] Graps, A. Historical Perspective, http://www.amara.com/IEEEwave.html, 2011. Diakses 3 September 2018.

[8] Jeong, S. Histogram-Based Color Image Retrieval, https://web.archive.org/web/20100818155513/http://scien.stanford.edu/pages/labsite/2002/ psych221/projects/02/sojeong/, 15 Maret 2001. Diakses 3 September 2018.

[9] Kalyan, R. \& Mukherjee J. Image Similarity Measure using Color Histogram, Color Coherence Vector, and Sobel Method, https://pdfs.semanticscholar.org/f274/a33656fc670ae30f3b74376eccdd47ceb000.pdf, 1 Januari 2013. Diakses 3 September 2018.

[10] Kaplan, I. Transform Matrix, http://bearcave.com/misl/misl_tech/wavelets/matrix/index.html, 30 September 2011. Diakses 3 September 2018.

[11] Natalia, Hendryli, J., Herwindiati, D. E. Batik Image Retrieval System Using Self Organizing Map, https://www.researchgate.net/publication/327852370_Batik_Image_Retrieval_System_Usi ng_Self_Organizing_Map, Januari 2018.

[12] Raschka, S. Linear Discriminant Analysis, http://sebastianraschka.com/Articles/2014_pythonda.html\#reading-in-the-dataset, 3 Agustus 2014.

[13] Sampath, S. Classifying image data, http://www.debugmode.com/imagecmp/classify.htm, 22 Oktober 2001. Diakses 3 September 2018.

[14] Surya \& Suryanto. Batik Indonesia Resmi Diakui UNESCO, https://www.antaranews.com/berita/156389/batik-indonesia-resmi-diakui-unesco, 2 Oktober 2009. Diakses 30 Agustus 2018.

[15] Tania, E. Optimisasi Pemilihan Feature Menggunakan Particle Swarm Optimization untuk Pengenalan Citra Motif Batik Tulis, Program Studi Teknik Informatika Fakultas Teknologi Informasi Universitas Tarumanagara (Skripsi tidak dipublikasikan), 2017.

[16] Tristanto, J; Hendryli, J; Herwindiati, D. E. Perancangan Aplikasi Repositori Berbasis Web dengan Fitur Pengenalan Motif Batik https://www.researchgate.net/publication/328060831_Classification_of_Batik_Motifs_Usi ng_Convolutional_Neural_Networks, Januari 2018.

[17] van Wijnen, B., Malaysia Batik, https://www.malaysiasite.nl/batikeng.htm, 5 Mei 2014. Diakses 30 Agustus 2018. 